\title{
Efficacy and tolerance of high-dose-rate brachytherapy boost after external radiotherapy in the treatment of squamous cell carcinoma of the anal canal
}

\author{
Emilien Bertin, MD',2, Karen Benezery, MD', Daniel Lam Cham Kee, MD', Eric François, MD'.3, Ludovic Evesque, MD'.3, \\ Mathieu Gautier, MSc', Jean-Pierre Gerard, MD, PhD', Jean-Michel Hannoun-Levi, MD, PhD',2, Alexander T Falk, MD, MSc',2 \\ 'Department of Radiation Oncology, Centre Antoine Lacassagne, 2 Université Cote d'Azur, ${ }^{3}$ Department of Medical Oncology, Centre Antoine \\ Lacassagne, Nice, France
}

\begin{abstract}
Purpose: The aim of this study was to evaluate the efficacy and toxicity of high-dose-rate brachytherapy (HDR-BT) boost in anal squamous cell carcinoma (ASCC).

Material and methods: This was a monocentric retrospective study involving patients treated by external irradiation ( \pm chemotherapy), with HDR-BT boost, for a localized ASCC. Clinical evaluation was performed every six months. Oncological results were analyzed with: local relapse-free survival (LRFS), colostomy-free survival (CFS), metastatic-free survival (MFS), disease-free survival (DFS), and overall survival (OS). Acute and late toxicities were collected (CTCV4.0) and LENT/SOMA score was performed.

Results: From May 2005 to January 2018, 46 patients (pts) were analyzed. The median follow-up was 61 months (10-145 months), the median age was 65 years (34-84 years), with a sex ratio $\mathrm{M} / \mathrm{F}=0.24$. The TNM classification was as follows: T1 - 13 pts $(21.7 \%), \mathrm{T} 2-34$ pts $(73.9 \%), \mathrm{T} 3-2$ pts $(4.3 \%), \mathrm{N}+-6$ pts $(13.1 \%)$. External beam radiotherapy (EBRT) delivered a median dose of 45 Gy (36-50.4 Gy) in 25 fractions, and HDR-BT 12 Gy (10-18 Gy) in 3 fractions. The median overall treatment time (OTT) was 58 days (41-101 days), with a median EBRT/brachytherapy interval of 17 days (4-60 days). Oncological findings showed 5-year rates of LRFS $81.2 \%$, MFS $88.7 \%$, DFS 70\%, and OS $90 \%$. All abdominoperineal amputations were performed in case of local relapse (4 pts, 8.7\%), leading to a 5-year CFS of 79.5\%. Acute urinary toxicities were frequent (G1 41.3\%, G2 4.3\%). The acute digestive toxicities were: G1 71.7\%, G2 6.5\%, and G3 2.2\%. The late urinary toxicities were: G1 4.3\%, G2 2.2\%, and G3 2.2\%. Late digestive toxicities were: G1 56.5\%, G2 8.7\%, G3 2.2\%, and G4 2.2\%.

Conclusions: In ASCC management, HDR-BT boost appears to be a treatment with a long-term acceptable toxicity profile, shorter than EBRT boost, with a reduction of side effects.

J Contemp Brachytherapy 2018; 10, 6: 522-531 DOI: https://doi.org/10.5114/jcb.2018.81025
\end{abstract}

Key words: anal squamous cell carcinoma, brachytherapy, boost, high-dose-rate, radiotherapy.

\section{Purpose}

Anal squamous cell carcinoma (ASCC) is a rare cancer with an estimated 30,000 new cases per year worldwide [1]. The increased incidence of ASCC reported in the last few decades $[2,3,4]$ has been linked to the raise of human papilloma virus (HPV) infection, which is more prevalent in the human immunodeficiency virus-positive (HIV+) population [5]. Treatment modalities for ASCC have evolved from radical surgery with abdominoperineal resection (APR) [6] to chemoradiotherapy (CRT), which is now the standard treatment for localized forms of ASCC
[7]. Current international recommendations advocate for a total dose of 36-45 Gy to the anal canal, mesorectum, and prophylactic lymph nodes [8], with an additional irradiation of 15 to 25 Gy to the anal tumor [9]. Moureau-Zabotto et al. showed that complementary irradiation could be performed by brachytherapy (BT) with better local control and less toxicity compared to an external beam radiotherapy (EBRT) boost [10]. According to the latest European recommendations [11], high-dose-rate brachytherapy (HDR-BT) can be used as a boost following standard chemoradiotherapy. A recent study showed that a boost with low-dose-
Address for correspondence: Dr. Alexander T Falk, MD, MSc, Department of Radiation Oncology, Centre Antoine Lacassagne, 33 Avenue de Valombrose, 06189 Nice, France, phone: +04 92031623 , fax: +04 920315 70, e-mail: alexander.falk@nice.unicancer.fr
Received: 25.07 .2018

Accepted: 15.11.2018

Published: 28.12.2018 
rate brachytherapy (LDR-BT) seems to have same clinical results but less toxicity than EBRT [12]. However, LDR-BT is not available anymore in Europe. HDR-BT is a recent technique and data on dose and toxicities are still scarce. The aim of this study is to report efficacy and toxicity of HDR-BT in the treatment of ASCC.

\section{Material and methods}

\section{Patient selection}

This retrospective single-institution study included patients with a histology proven squamous cell carcinoma and have received EBRT, followed by HDR-BT. Patients underwent chemotherapy after a multidisciplinary consultation. Initial evaluation was made by clinical examination with digital rectal examination and dated schema, followed by computed tomography (CT) scan, and endorectal endoscopy, magnetic resonance imaging (MRI), or positron emission tomography CT (PET-CT). We used the UICC-AJCC TNM classification, $7^{\text {th }}$ edition (2011) to classify the tumor. Eligible patients were non-metastatic, and the circumference of the initial tumor had to be less than $2 / 3$ of the anal canal. Patients that could not undergo general anesthesia were excluded.

\section{Radiotherapy}

External beam radiotherapy was delivered by intensity modulated radiotherapy (IMRT) or 3-dimensional technique. Patients received between $45 \mathrm{~Gy}$ to $46 \mathrm{~Gy}$ in 1.8 or $2 \mathrm{~Gy} /$ fraction. Final dose prescription was left to radiotherapist's discretion according to last recommendation and patient's characteristics or side effects. As stated by the International Commission on Radiation Units Measurements (ICRU), the prescription was made depending on tumor size and the risk of lymph node involvement to the ICRU point, and planning target volume (PTV) was defined as 0.7 to 1 -centimeter margin around the clinical target volume (CTV) in all directions.

\section{Chemotherapy}

According to our digestive tumor multidisciplinary board, patients with a tumor classified as $\mathrm{T} \geq 2$ or

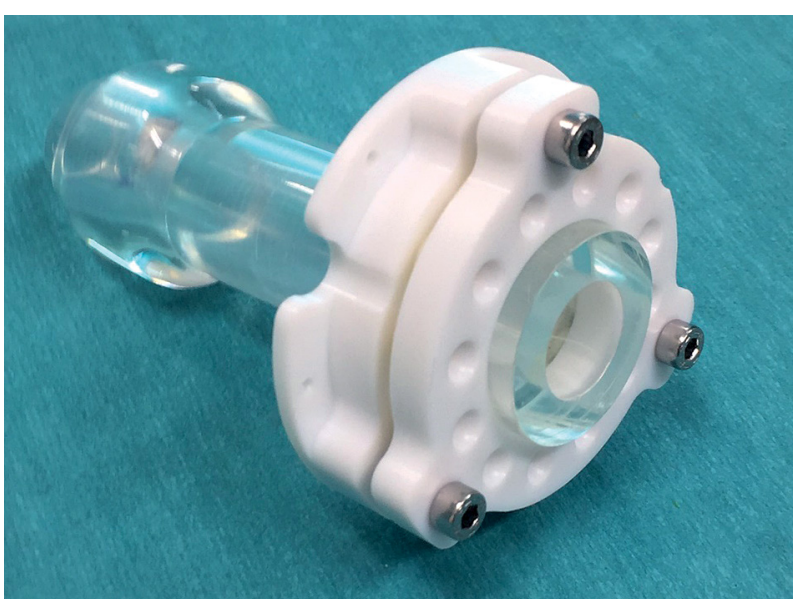

Fig. 1. Brachytherapy applicator
$\mathrm{N} \geq 1$ needed systemic treatment. They received concomitant chemotherapy with two cycles of a combination of 5-fluoro-uracil and mitomycine or cisplatin. The standard dose of 5 -FU was $1,000 \mathrm{mg} / \mathrm{m}^{2} / 96$ hours on day 1 to 4 and day 29 to 32 . Mitomycine was delivered at the dose of $10 \mathrm{mg} / \mathrm{m}^{2}$ on day 1 and 29 , and cisplatin $60 \mathrm{mg} / \mathrm{m}^{2}$ on day 1 and 29 .

\section{Brachytherapy}

Patients were hospitalized in a non-shielded room from the day before the intervention to the day after the removal of the material. BT was planned 7 to 14 days after the end of EBRT to allow healing of the post-radiation perineal epithelitis. BT treatment could be rescheduled depending on the clinical condition of the patient or technical constraints. Prior intestinal preparation consisted of a fiber-free diet for five days and enema before the intervention. The implantation was conducted under general anesthesia and preceded by a clinical evaluation of local response after EBRT and chemotherapy. Complete response was defined as a complete clinical response with digital examination and anuscopy, partial response was defined in case of tumor residue at the digital examination and anuscopy. Needles (Sharp Needles ${ }^{\mathrm{TM}}$; Nucletron, an Elekta company, Elekta AB, Stockholm, Sweden) were implanted according to the Paris system recommendations [13] and taking into account the pre-treatment target volume (based on the initial schema), with a minimal distance of 4 to $5 \mathrm{~mm}$ from the needles to the anal canal mucosa. We used a dedicated circular perineal template punched by a total of 10 holes (every $12 \mathrm{~mm}$ ). A plastic tube (20 mm in external diameter, Figure 1) was placed into the anal canal and fixed to the perineal template, which was finally sutured to the skin. A CT-scan was then completed, and treatment plan was established (Figure 2) on Oncentra ${ }^{\circledR}$ Brachy software (v. 4.5.2, Elekta). Clinical evaluation of tumor bed and tumor residue at the time of implantation and also the pre-treatment volume was considered for the HDR boost CTV. If the clinical response was complete, only $12 \mathrm{~Gy}$ in three fractions over two days were delivered. However, in case of partial response, 15 Gy in three fractions over two days were administered with HDR microSelectron ${ }^{\circledR}$ V2 Digital

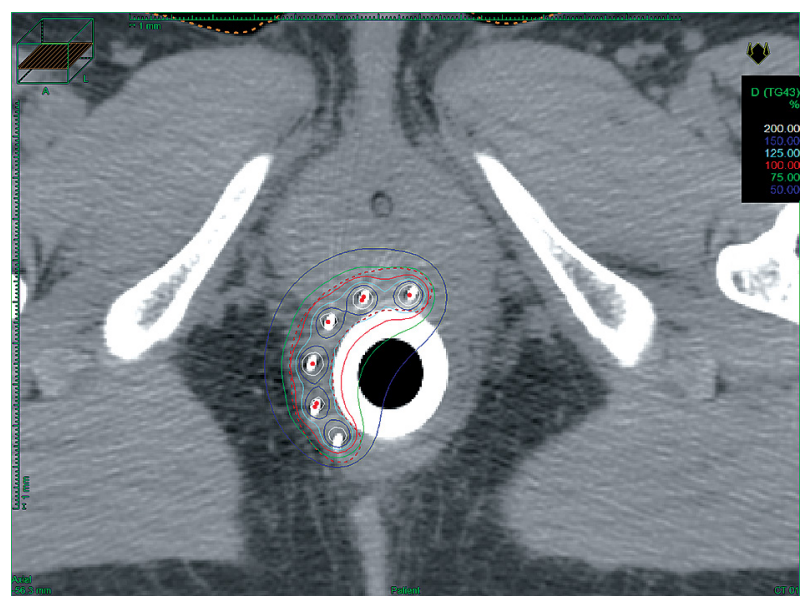

Fig. 2. Dosimetry example 
platform (Elekta) using Iridium ${ }^{192}$ sources. A minimum interval of six hours between each fraction was respected.

\section{Clinical evaluation}

Each patient was examined by a radiotherapist or an oncologist every six months for five years. After five years, the follow-up was performed by the patient's general practitioner. In this study, we specifically evaluated acute and late toxicities to estimate patient's quality of life after BT. According to the late effects normal tissue (LENT)/subjective, objective, management, analytic (SOMA) score [14] for late radiation effects of the anus, we evaluated patients with this score to analyze the long-term side effects of this technique [15]. In January 2018, we retrospectively called back patients to propose a LENT/SOMA adapted questionnaire (Table 1). Their score was calculated, and the results before and after treatment were compared.

\section{Endpoints}

The primary endpoint of this study was the overall survival (OS). Secondary endpoints were local relapse-free survival (LRFS), colostomy-free survival (CFS), metastatic-free survival (MFS), and disease-free survival (DFS). LENT/SOMA score and the National Cancer Institute (NCI) Common Terminology Criteria for Adverse Events (CTCAE) version 4.0 [16] were used to evaluate toxicities.

\section{Statistical analysis}

Population's characteristics were described using minimum, maximum, mean, and median values. Endpoints were defined as follows: OS was the interval between date of diagnostic (histologically proven on biopsies) and the date of death from any cause, LRFS was the interval between date of diagnostic and date of local recurrence, CFS was the interval between date of diagnostic and date of colostomy from any cause, MFS was the interval between date of diagnostic and date of first metastasis, DFS was the interval between date of diagnostic and date of local recurrence or distant recurrence, overall treatment time (OTT) was the interval between date of the first day of treatment and last day of treatment. Dosimetric results included the dose delivered to $90 \%$ of the CTV $\left(\mathrm{D}_{90}\right)$, the dose delivered to $100 \%$ of the CTV $\left(D_{100}\right)$, the volume receiving $100 \%, 150 \%$, and $200 \%$ of the prescribed dose (respectively $\mathrm{V}_{100}, \mathrm{~V}_{150}$, and $\mathrm{V}_{200}$ ), and the dose homogeneity index (DHI: $\left.\left[\mathrm{V}_{100}-\mathrm{V}_{150}\right] / \mathrm{V}_{100}\right)$. We also compared LENT/SOMA scores before and after radiotherapy using Chi-squared test. All survivals were estimated according to the Kaplan-Meier method, with the use of SPSS statistical software (20.0 IBM Corporation). This study was approved by a local institutional ethics committee (ethical committee number: 2209548).

\section{Results}

\section{Population}

A total of 46 patients were analyzed between May 2005 and January 2018, with a median follow-up of 61 months (9-145 months). The median age was 65 years (3484 years). The male/female sex-ratio was 0.24 . According to the Eastern Cooperative Oncology Group (ECOG), performance status (PS) of forty-one patients $(89.1 \%)$ was 0 and the other five patients $(10.9 \%)$ had a PS of 1 . Patients' characteristics are presented in Table 2.

\section{Tumor and treatment}

The median initial tumor size was $3 \mathrm{~cm}(0.7-6 \mathrm{~cm})$ and 7 patients $(15.2 \%)$ had anal margin invasion. Sixteen biopsies $(34.7 \%)$ tested for the HPV 16 serotype were positive. Thirty-three patients $(71.7 \%)$ underwent chemotherapy, among which 26 patients $(56.5 \%)$ received 5-FU and mitomycine-C. Six patients (13\%) received a combination of 5-fluoro-uracil and cisplatin. Twenty-five patients (54.3\%) were treated with IMRT. Median dose of EBRT was $45 \mathrm{~Gy}$ (36-50.4) in 20 to 28 fractions. Median dose of BT boost was 12 Gy (10-18 Gy), with 2.5 to 5 Gy in two to six fractions; most patients received 3 fractions of 4 Gy (73.9\%). Four patients did not receive the standard dose of $45 \mathrm{~Gy}$ : one patient received $36 \mathrm{~Gy}$ because of previous radiotherapy for cervical cancer, two patients stopped before $45 \mathrm{~Gy}$ due to digestive toxicities, and one patient received 50.4 Gy at the physician's discretion. One patient received a $10 \mathrm{~Gy}$ brachytherapy boost in two fractions because of hospitalization duration constraint, which corresponded in equivalent dose at 2 Gy per fraction, a dose similar to 12 Gy in three fractions. Another patient received $18 \mathrm{~Gy}$ in 5 fractions over three days because he only received 36 Gy in EBRT due to previous radiotherapy history. The median duration of brachytherapy was 2 days [2,3]. Median number of needles was 5 (4-18). Details of dosimetric data are reported in Table 3.

\section{Clinical results}

The 5-year overall survival (OS), 5-year local relapse-free survival (LRFS), cumulative rate of local recurrence (CRLR), 5-year colostomy-free survival (CFS), 5-year metastatic-free survival (MFS), and the 5-year disease-free survival (DFS) were 90\% (SE 4.7\%), 81.2\% (SE 6.6\%), 15.2\% (SE 6.1\%), 79.5\% (SE 7.2\%), 88.7\% (SE 4.8\%), and 70\% (SE $7.6 \%)$, respectively. At the end of the follow-up, 7 patients $(15.2 \%)$ had a local recurrence (Figures 3-7).

\section{Colostomy}

Seven patients had a colostomy: one patient $(2.2 \%)$ because of grade 4 ulceration but was able to benefit a restoration of continuity, one patient $(2.2 \%)$ after grade 4 anal incontinence, four patients $(8.7 \%)$ after APR because of a local recurrence, and one patient $(2.2 \%)$ had a local resection with a temporary colostomy because of a LR.

\section{Toxicity}

Gastro-intestinal (GI) acute side effects were frequent but not severe: $33(71.7 \%)$ grade $1(\mathrm{G} 1)$ and $3(6.5 \%)$ grade 2 (G2). Acute genito-urinary (GU) side effects were also frequent but not severe: 19 (41.3\%) G1, 2 (4.3\%) G2. Only one patient $(2.2 \%)$ had a grade 3 (G3) acute toxicity, a rectal pain, managed with medication. Late GI toxicities 
Table 1. LENT/SOMA questionnaire

\begin{tabular}{|c|c|}
\hline \multirow[t]{5}{*}{ Do you have urgency? } & $0-$ no \\
\hline & 1 - occasional (<1/week) \\
\hline & 2 -intermittent (1/week) \\
\hline & 3 - persistent (1/day) \\
\hline & 4- refractory (constant) \\
\hline \multirow{5}{*}{$\begin{array}{l}\text { Do you have mucosal } \\
\text { loss? }\end{array}$} & $0-$ no \\
\hline & 1 - occasional (<1/week) \\
\hline & 2 -intermittent (1/week) \\
\hline & 3 - persistent (1/day) \\
\hline & 4- refractory (constant) \\
\hline \multirow{5}{*}{$\begin{array}{l}\text { Do you have loss of } \\
\text { sphincter control? }\end{array}$} & $0-$ no \\
\hline & 1 - occasional (<1/week) \\
\hline & 2 -intermittent (1/week) \\
\hline & 3 - persistent (1/day) \\
\hline & 4- refractory (constant) \\
\hline \multirow{5}{*}{$\begin{array}{l}\text { Management: Do } \\
\text { you use incontinence } \\
\text { pads? }\end{array}$} & $0-$ no \\
\hline & 1 - occasional (<1/week) \\
\hline & 2 -intermittent (1/week) \\
\hline & 3 - persistent (1/day) \\
\hline & 4- refractory (constant) \\
\hline \multirow{5}{*}{$\begin{array}{l}\text { What is your stool } \\
\text { frequency? }\end{array}$} & 0 - none or $1 /$ day \\
\hline & $1-2$ to $4 /$ day \\
\hline & $2-4$ to $8 /$ day \\
\hline & $3->8 /$ day \\
\hline & 4-uncontrolled diarrhea \\
\hline \multirow{5}{*}{$\begin{array}{l}\text { Management: Do you } \\
\text { use antidiarrheals? }\end{array}$} & $0-$ no \\
\hline & 1 - occasional ( $\leq 2 /$ week) \\
\hline & 2 -regular (> 2/week) \\
\hline & 3 -multiple (> 2/day) \\
\hline & $\begin{array}{l}4 \text { - surgical intervention/permanent } \\
\text { colostomy }\end{array}$ \\
\hline \multirow{5}{*}{$\begin{array}{l}\text { Do you have anal } \\
\text { pain? }\end{array}$} & $0-$ no \\
\hline & 1-occasional and minimal \\
\hline & 2 -intermittent and tolerable \\
\hline & 3 - persistent and intense \\
\hline & 4- refractory and excruciating \\
\hline
\end{tabular}

\begin{tabular}{|c|c|}
\hline \multirow{5}{*}{$\begin{array}{l}\text { Management: Do you } \\
\text { use pain medication? }\end{array}$} & $0-$ no \\
\hline & 1 - occasional non-narcotic (<1/week) \\
\hline & 2 - regular non-narcotic (1/week) \\
\hline & 3 - regular narcotic (1/week) \\
\hline & 4 - surgical intervention \\
\hline \multirow{5}{*}{$\begin{array}{l}\text { Do you have rectal } \\
\text { bleeding? }\end{array}$} & $0-$ no \\
\hline & $1-$ occult \\
\hline & 2-occasionally (> 2/week) \\
\hline & 3 - persistent/daily \\
\hline & 4 - gross hemorrhage \\
\hline \multirow{5}{*}{$\begin{array}{l}\text { Management: Do } \\
\text { you need treatment } \\
\text { against this bleeding? }\end{array}$} & $0-$ no \\
\hline & 1 - stool softener, iron therapy \\
\hline & 2-occasional transfusion \\
\hline & 3 - frequent transfusion \\
\hline & $\begin{array}{l}4 \text { - surgical intervention/permanent } \\
\text { colostomy }\end{array}$ \\
\hline \multirow{5}{*}{$\begin{array}{l}\text { Do you have anal } \\
\text { ulceration? }\end{array}$} & $0-$ no \\
\hline & $1-$ superficial $\left(\leq 1 \mathrm{~cm}^{2}\right)$ \\
\hline & 2 - superficial $\left(>1 \mathrm{~cm}^{2}\right)$ \\
\hline & 3-deep ulcer \\
\hline & 4-perforation, fistulae \\
\hline \multirow{5}{*}{$\begin{array}{l}\text { Management: Do } \\
\text { you need treatment } \\
\text { against this } \\
\text { ulceration? }\end{array}$} & $0-$ no \\
\hline & 1 - stool softener, diet modification \\
\hline & 2-occasional steroids \\
\hline & $\begin{array}{l}3 \text { - steroids per enema, hyperbaric } \\
\text { oxygen }\end{array}$ \\
\hline & $\begin{array}{l}4 \text { - surgical intervention/permanent } \\
\text { colostomy }\end{array}$ \\
\hline \multirow{5}{*}{$\begin{array}{l}\text { Do you have anal } \\
\text { stricture? }\end{array}$} & $0-$ no \\
\hline & $\begin{array}{l}1->2 / 3 \text { normal diameter with dil- } \\
\text { atation }\end{array}$ \\
\hline & $\begin{array}{l}2-1 / 3 \text { to } 2 / 3 \text { normal diameter with } \\
\text { dilatation }\end{array}$ \\
\hline & $3-<1 / 3$ normal diameter \\
\hline & 4-complete obstruction \\
\hline \multirow{5}{*}{$\begin{array}{l}\text { Management: Do } \\
\text { you need treatment } \\
\text { against this stricture? }\end{array}$} & $0-$ no \\
\hline & 1 -diet modification \\
\hline & 2-occasional dilatation \\
\hline & 3 - regular dilatation \\
\hline & $\begin{array}{l}4 \text { - surgical intervention/permanent } \\
\text { colostomy }\end{array}$ \\
\hline
\end{tabular}


Table 2. Patient, tumor and treatment characteristics

\begin{tabular}{|c|c|c|}
\hline Characteristics & Number (\%) $n=46$ & Median (interval) \\
\hline Age (years) & & 65.1 (34-84 years) \\
\hline \multicolumn{3}{|l|}{ Gender } \\
\hline Men & $9(19.6 \%)$ & \\
\hline Women & 37 (80.4\%) & \\
\hline \multicolumn{3}{|l|}{ Tumor stage } \\
\hline $\mathrm{T} 1$ & $10(21.7 \%)$ & \\
\hline $\mathrm{T} 2$ & 34 (73.9\%) & \\
\hline T3 & $2(4.3 \%)$ & \\
\hline $\mathrm{T} 4$ & 0 & \\
\hline \multicolumn{3}{|l|}{ Lymph node stage } \\
\hline NO & $40(87 \%)$ & \\
\hline N1 & $5(10.9 \%)$ & \\
\hline N2 & $1(2.2 \%)$ & \\
\hline Tumor ulceration & 19 (41.3\%) & \\
\hline Chemotherapy & $33(71.7 \%)$ & \\
\hline EBRT dose (Gy) & & $45(36-52)$ \\
\hline BT boost dose (Gy) & & $12(10-18)$ \\
\hline OTT (days) & & $58(41-101)$ \\
\hline $\begin{array}{l}\text { Interval EBRT/BT } \\
\text { (days) }\end{array}$ & & $17(4-60)$ \\
\hline
\end{tabular}

EBRT - external beam radiation therapy; BT - brachytherapy; OTT - overall treatment time

were mainly G1 (56.5\%) and we observed a few late GU toxicities: 2 (4.3\%) G1 and 1 (2.2\%) G2. Late high toxicities G3 and G4 remained very low: for GI toxicity one patient (2.2\%) G3, and one (2.2\%) G4; for GU toxicity, only one patient $(2.2 \%)$ G3. All toxicities are detailed in Tables 4 and 5. Concerning LENT/SOMA scores, 27 pretreatment

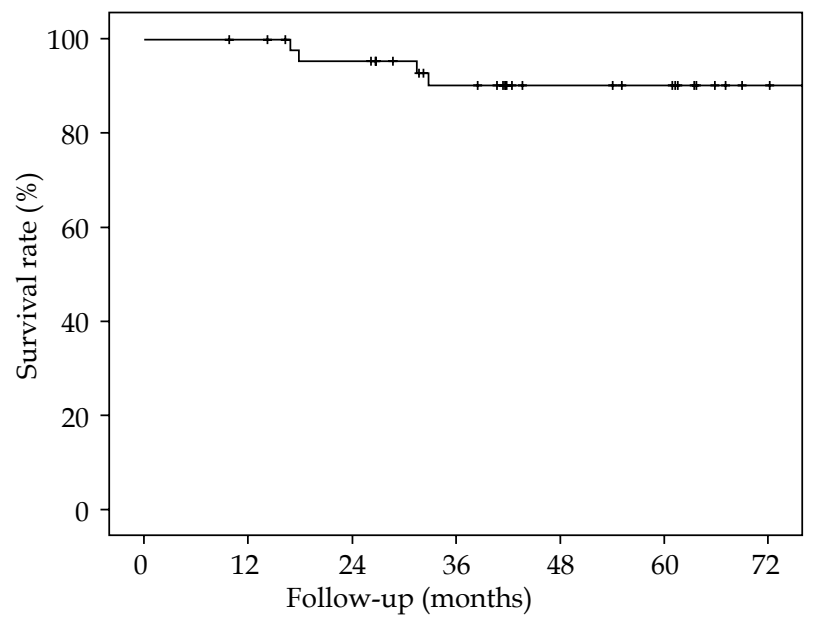

Fig. 3. Kaplan-Meier curves for overall survival
Table 3. Dosimetric data

\begin{tabular}{lcc} 
Data & Median & Interval \\
\hline CTV & 18.2 & {$[7.58-46.69]$} \\
\hline$D_{90 \%}$ & 106 & {$[32-117]$} \\
\hline EQD2 $\alpha \beta 10(G y)$ & 14.9 & {$[5.47-21.87]$} \\
\hline EQD2 $\alpha \beta 3$ (Gy) & 17.9 & {$[6.86-26.45]$} \\
\hline$D_{100 \%}$ & 78 & {$[20-98]$} \\
\hline EQD2 $\alpha \beta 10(G y)$ & 11 & {$[3.35-18.7]$} \\
\hline EQD2 $\alpha \beta 3$ (Gy) & 13.2 & {$[4.2-21.6]$} \\
\hline$V_{100}$ & & \\
\hline$\%$ & 96 & {$[58-100]$} \\
\hline$C C$ & 17 & {$[7.1-45.8]$} \\
\hline$V_{150}$ & & {$[26-57]$} \\
\hline$\%$ & 36 & {$[2.53-26.6]$} \\
\hline$C C$ & 6.9 & {$[10-26]$} \\
\hline$V_{200}$ & & {$[1.2-11.7]$} \\
\hline$C C$ & 17 & {$[0.42-0.69]$}
\end{tabular}

CTV-clinical target volume; $D_{90}$ - dose delivered to $90 \%$ of the $C T V ; E Q D 2 \alpha \beta 10$ - equivalent dose at 2 Gy per fraction for $\alpha \beta 10$ (tumor): EOD2 $\alpha \beta 3$ - equivalent dose at $2 \mathrm{~Gy}$ per fraction for $\alpha \beta 3$ (normal tissues); $V_{100}$ - volume receiving $100 \%$ of the prescribed dose; $V_{150}$ - volume receiving $150 \%$ of the prescribed dose; $V_{200}$ - volume receiving $200 \%$ of the prescribed dose; DHI - dose homogeneity index

and 28 post-treatment scores were collected. Mean score was 0.097 before treatment, and 0.5029 after treatment, with a statistically significant difference $(p=0.001)$. Median score was $0(0-0.46)$ before treatment and $0.46(0-1.18)$ after treatment.

\section{Discussion with conclusions}

Brachytherapy boost for ASCC appears to be an effective treatment $[10,17]$. Recently, HDR-BT has been developed and several studies have demonstrated its feasibility and effectiveness [17]. This study is based on the early results of Falk et al. [18] and presents late results. It also considers the quality of life with the LENT/ SOMA score.

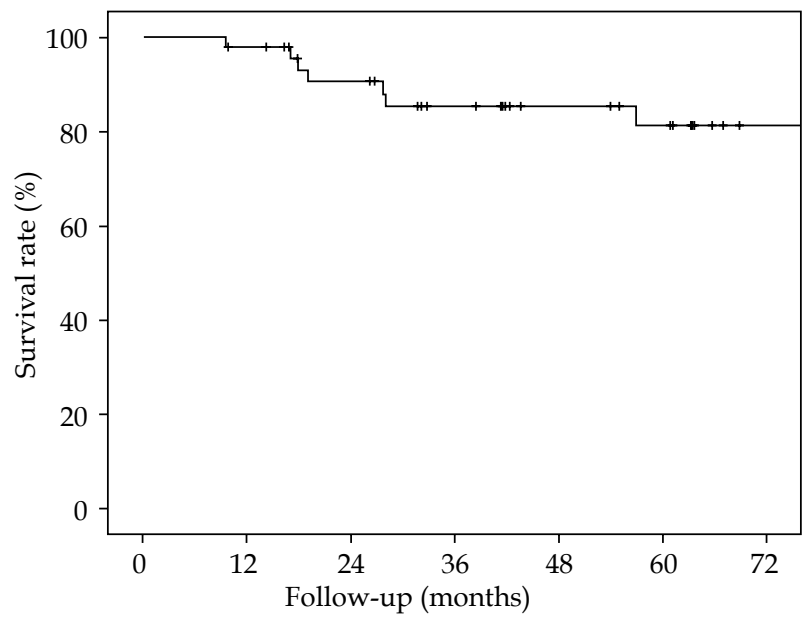

Fig. 4. Kaplan-Meier curves for local relapse-free survival 
At 5 years, CRLR was $15.2 \%, 7$ patients had a LR, which seems similar to data reported in the literature: Cordoba et al. described a 5-year CRLR of 10.1\% (11 patients) [12], and Moureau-Zabotto et al. a 5-year CRLR of $11 \%$ (18 patients) [10]. However, Gryc et al. had a 5-year CRLR of $24.8 \%$ (45 patients) for PDR-BT boost [19]. Concerning EBRT boost series, Hannoun-Levi et al. found a LR rate of $26.3 \%$ (20 patients) [20], and Moureau-Zabotto et al. a 5-year CRLR of 32\% (13 patients) [10]. In EBRT, Northover et al. found a 5-year CRLR of 32.3\% (95 patients) [21], and Ajani et al. found a 5-year CRLR of $25 \%$ (81 patients) [22]. The Kiel group had a local control of $89 \%$ but no information concerning patient selection were available [23]. A recent systematic review of brachytherapy boost, all techniques combined, found a median 5-year local control of $78.6 \%$ (7 studies) and a median 5-year CFS of $76.1 \%$ (5 studies) [24]. In our series, by analyzing the 7 patients who had a LR, we noticed that one of these patients was infected by the human immunodeficiency virus (HIV), which is a risk factor of recurrence and complications [25]. Two of these patients had an ulcerated tumor, which is a negative prognostic factor. Moreover, tumor size and $\mathrm{T}$ stage have been recognized as pejorative prognostic factors [26]. Of these patients, 4 were T2 (with an initial tumor size more than 3 centimeters). Five patients had a longer interval between EBRT and BT of 1 to 43 days more than the median interval of 17 days. One patient had an interval between RT/BT of 60 days because of acute toxicity during EBRT (stop at the dose of $37.8 \mathrm{~Gy}$ ). As described in the literature [10], reduction of OTT could improve local control and accordingly, we will make an effort to reduce OTT in our department. Overall, patients with a LR presented unfavorable prognostic factors that could explain these results.

Concerning the treatment tolerance, acute toxicities were frequent but not severe, which is a similar profile compared to LDR or PDR-BT, but late side effects seemed to be less frequent with HDR-BT $[12,27]$. In fact, previous study found severe (at least G3) late toxicities rate from $9 \%$ to $13 \%$ with LDR-BT $[28,29]$; however, one study of HDR-BT by Kapoor et al. did not describe any G3 or more toxicities [30]. In our study, only $6.5 \%$ severe late toxicities were observed. That could be explained by a DHI (median $=0.62$, SE [0.42-0.69]) higher than Kapoor et al . (median DHI = 0.83, SE [0.55-0.98] [30]). Modern external beam radiotherapy with boost also seems to have more toxicities than HDR-BT. Kachnic et al. had 21\% gastrointestinal/genitourinary G3 and G4 [31]. We excluded patients with a circumference of the initial tumor superior of the $2 / 3$ of the canal anal to avoid necrosis [24]. Only two patients had a colostomy due to toxicities: one ulceration (in HIV-infected patient with high viral load at the time of diagnosis and treatment) and one anal incontinence; for the 5 other patients, it was because of local recurrence. Deniaud et al. had similar results with EBRT boost: $5 \%$ of G3 late toxicities and one colostomy due to incontinence [32]. The patient who presented G4 incontinence had an epidermoid carcinoma histology with T3 N1 stage and an initial tumor size of $4.5 \mathrm{~cm}$ with ulceration. This patient received chemotherapy by cisplatin and a total dose in

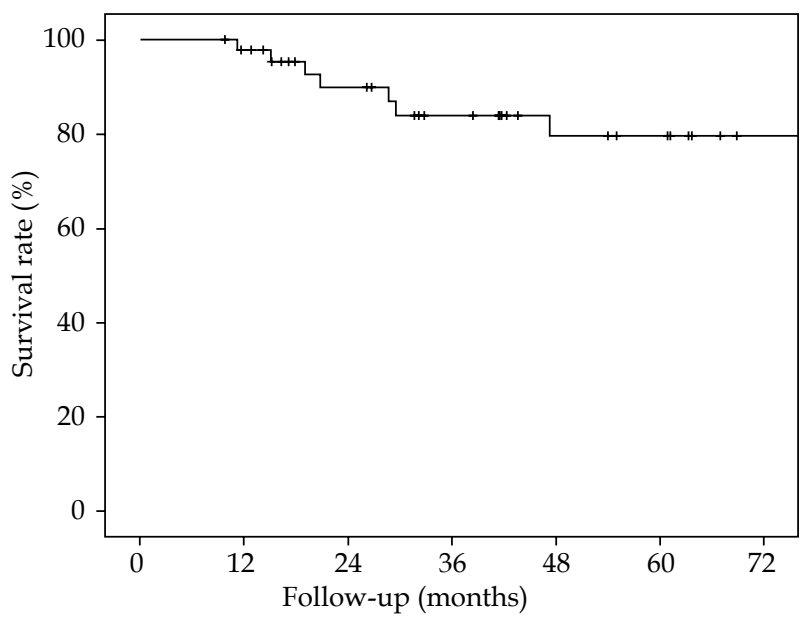

Fig. 5. Kaplan-Meier curves for colostomy-free survival

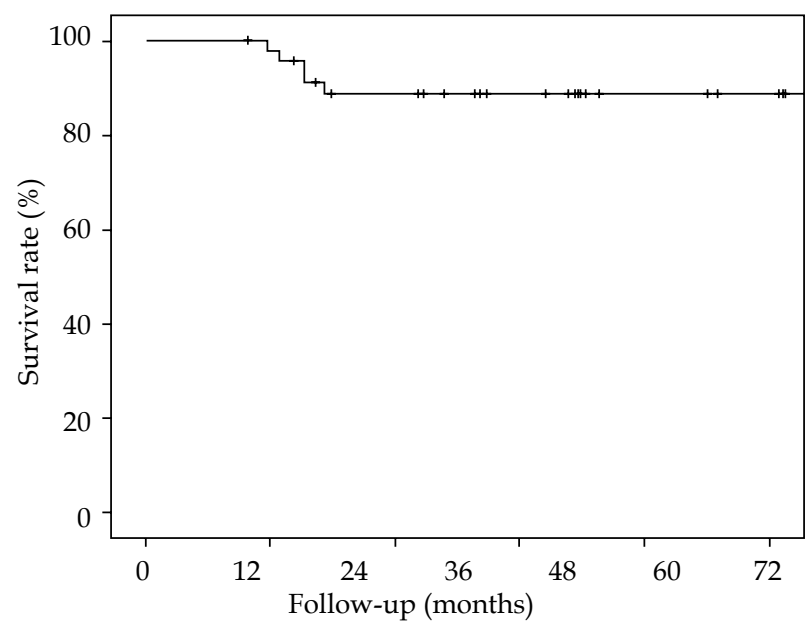

Fig. 6. Kaplan-Meier curves for metastasis-free survival

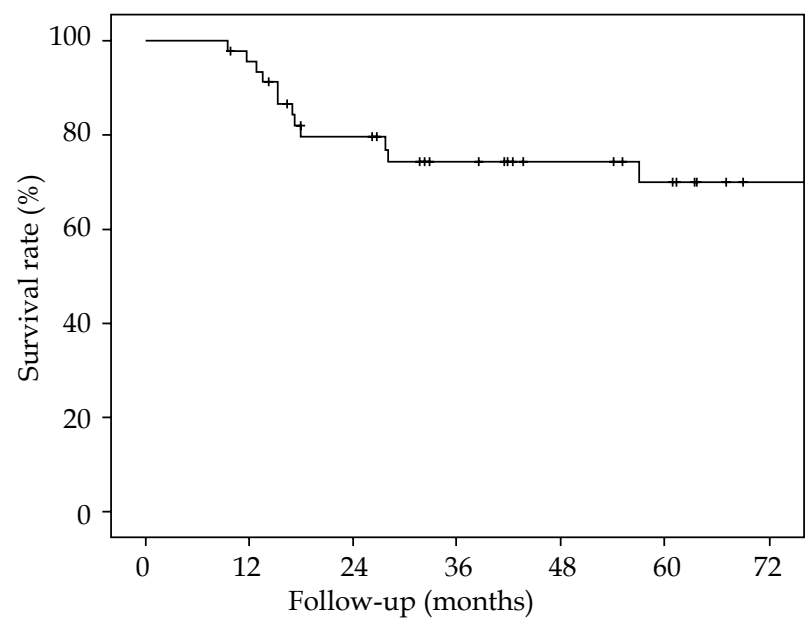

Fig. 7. Kaplan-Meier curves for disease-free survival

EBRT of 46 Gy with a 3-dimensional technic. A boost of $15 \mathrm{~Gy}$ in 3 fractions of 5 Gy were delivered in BT, half of the circumference was treated. The patient who presented G4 ulceration had a stage T2 N1, with an initial tumor size of $3.5 \mathrm{~cm}$ with ulceration. This patient received chemotherapy by cisplatin and a total dose in EBRT of 45 Gy 
Table 4. Toxicities

\begin{tabular}{|c|c|c|c|c|c|}
\hline & & & Grade & & \\
\hline & G1 (\%) & G2 (\%) & G3 (\%) & G4 (\%) & All (\%) \\
\hline Acute $(n=4$ & & & & & \\
\hline $\mathrm{Gl}$ & $33(71.7)$ & $3(6.5)$ & $1(2.2)$ & 0 & $37(80.4)$ \\
\hline $3 D$ & $16(34.8)$ & $3(6.5)$ & 0 & 0 & 19 (41.3) \\
\hline IMRT & $17(37)$ & 0 & $1(2.2)$ & 0 & 18 (39.1) \\
\hline GU & $19(41.3)$ & $2(4.3)$ & 0 & 0 & $21(45.7)$ \\
\hline $3 D$ & $5(10.9)$ & $1(2.2)$ & 0 & 0 & $6(13)$ \\
\hline IMRT & $14(30.4)$ & $1(2.2)$ & 0 & 0 & $15(32.6)$ \\
\hline Highest $(n=$ & & & & & \\
\hline $\mathrm{Gl}$ & $23(50)$ & $7(15.2)$ & $3(6.5)$ & $3(6.5)$ & $36(78.3)$ \\
\hline $3 D$ & $11(23.9)$ & $3(6.5)$ & $3(6.5)$ & $2(4.3)$ & 19 (41.3) \\
\hline IMRT & $12(26.1)$ & $4(8.7)$ & 0 & $1(2.2)$ & $17(37)$ \\
\hline $\mathrm{GU}$ & $10(21.7)$ & $2(4.3)$ & 0 & $1(2.2)$ & $13(28.3)$ \\
\hline $3 D$ & $6(13)$ & $1(2.2)$ & 0 & 0 & $7(15.2)$ \\
\hline IMRT & $4(8.7)$ & $1(2.2)$ & 0 & $1(2.2)$ & $6(13)$ \\
\hline Late $(n=44$ & & & & & \\
\hline $\mathrm{Gl}$ & $26(56.5)$ & $4(8.7)$ & $1(2.2)$ & $1(2.2)$ & $32(69.9)$ \\
\hline $3 D$ & 15 (32.6) & 0 & $1(2.2)$ & 0 & $16(34.8)$ \\
\hline IMRT & $11(23.9)$ & $4(8.7)$ & 0 & $1(2.2)$ & $16(34.8)$ \\
\hline GU & $2(4.3)$ & $1(2.2)$ & $1(2.2)$ & 0 & $4(8.7)$ \\
\hline $3 D$ & $2(4.3)$ & $1(2.2)$ & 0 & 0 & $3(6.5)$ \\
\hline IMRT & 0 & 0 & $1(2.2)$ & 0 & $1(2.2)$ \\
\hline
\end{tabular}

G1-grade 1; G2 - grade 2; G3-grade 3; G4 - grade 4; GI - gastro-intestinal; GU - genito-urinary; IMRT-patients treated by intensity modulated radiotherapy; $3 D$ - patients treated by 3-dimensional technique; adverse events were graded with the common terminology criteria for adverse events version 4.0

by 3-dimensional technic. A boost of $12 \mathrm{~Gy}$ in 3 fractions of 4 Gy were delivered in BT, with less than half of the circumference treated. New procedures using multiparametric imaging with MRI-compatible applicator to define the clinical target volume are feasible and could reduce the canal anal irradiation and toxicities [33].

We decided to evaluate patients before and after treatment with the LENT/ SOMA score to have an idea of the effect of the treatment on patients' quality of life. Many patients had rectal symptoms before treatment, therefore, we found relevant to use this score to compare before and after treatment. The variation between LENT/ SOMA score pre and post-treatment seemed to be significantly different and clinically relevant. Most frequently, patients reported intestinal disorders such as urgency, loss of sphincter control, and diarrhea.

In addition, HDR-BT boost reduces OTT with a median duration of BT boost of 2 days against 14 days for EBRT boost [10]. It results in a reduction of OTT (58 days [41-101] in our study vs. 85 days [45-141] for exclusive EBRT) [10] and must be taken into consideration for a cost-effectiveness analysis and patients' comfort. HDR allows less constraints than other BT techniques; the patient does not need to be hospitalized in a shielded-room, medical and paramedical staff are less prone to be exposed to radiation.

This study has some limitation; it was a retrospective monocentric study with a limited number of patients, but ASCC remains a rare disease and it is unlikely that randomized clinical trials will be performed to compare HDR boost. This database collects data since May 2005; at the beginning, we did not have IMRT available in our department. Since 2010, all patients were treated with IMRT.

In ASCC management, HDR-BT boost after radiochemotherapy appears to be a feasible treatment with acceptable toxicities and good efficacy. It allows a partial anal canal irradiation with long-term toxicities similar or lower than other boost techniques. While HDR brachytherapy is progressively used around the world, it is very unlikely that there will be randomized data to support HDR-BT in the near future. Retrospective and observa- 
Table 5. All toxicities

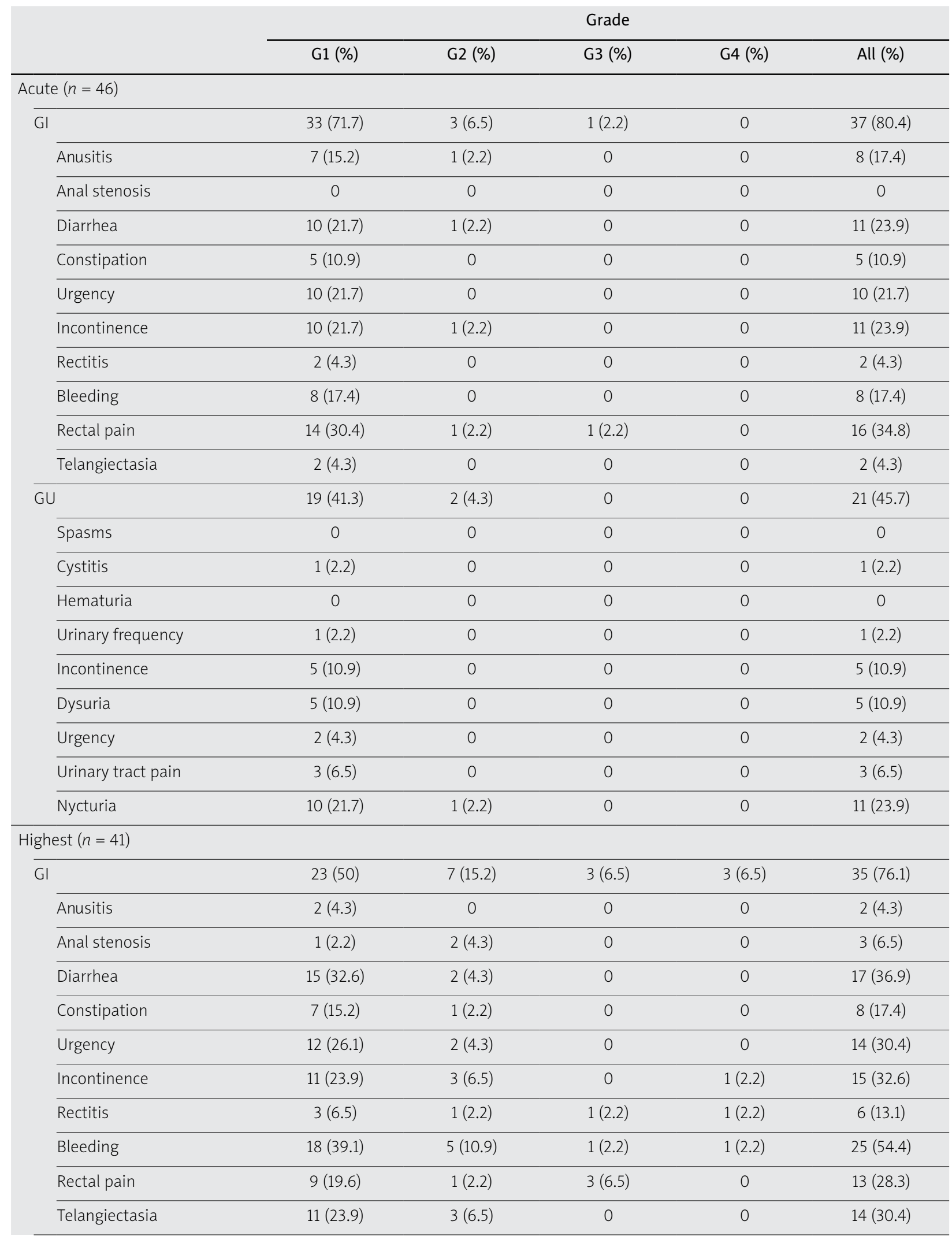


Table 5. Cont.

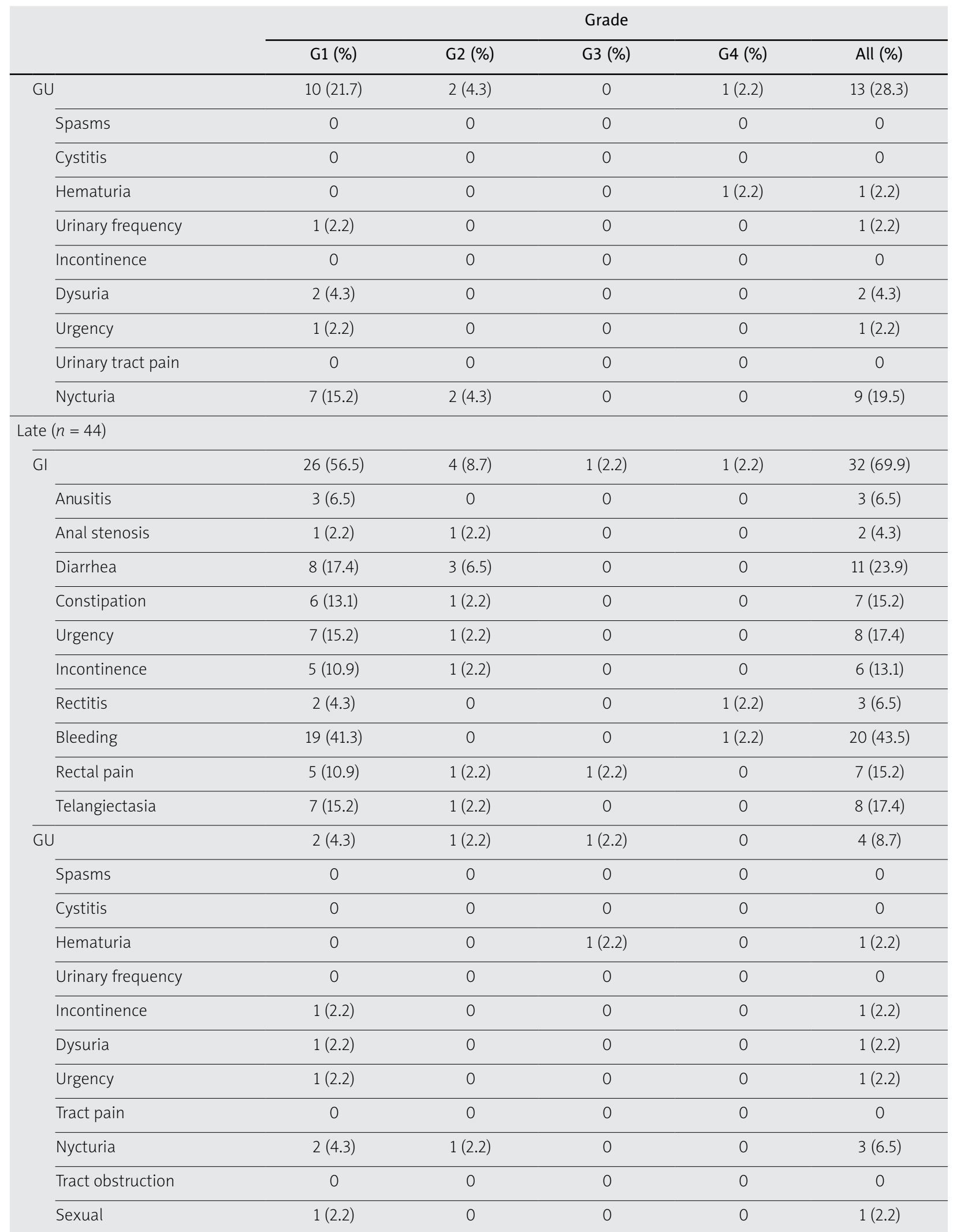

G1 - grade 1; G2 - grade 2; G3-grade 3; G4 - grade 4; GI -gastro-intestinal; GU - genito-urinary; adverse events were graded with the common terminology criteria for adverse events version 4.0 
tional prospective studies are currently the highest level of evidence to support this technique.

\section{Acknowledgements}

The authors would like to thank Caroline C. Escoubas, $\mathrm{PhD}$, for reviewing and proofing our manuscript.

\section{Disclosure}

Authors report no conflict of interest.

\section{References}

1. Abramowitz L, Jacquard A-C, Jaroud F et al. Human papillomavirus genotype distribution in anal cancer in France: The EDiTH V study. Int J Cancer 2011; 129: 433-439.

2. Robinson D, Coupland V, Møller H. An analysis of temporal and generational trends in the incidence of anal and other HPV-related cancers in Southeast England. Br J Cancer 2009; 100: 527-531.

3. Nielsen A, Munk C, Kjaer SK. Trends in incidence of anal cancer and high-grade anal intraepithelial neoplasia in Denmark, 1978-2008. Int J Cancer 2012; 130: 1168-1173.

4. Johnson LG, Madeleine MM, Newcomer LM, et al. Anal cancer incidence and survival: The Surveillance, Epidemiology, and End Results experience, 1973-2000. Cancer 2004; 101: 281-288.

5. Colón-López V, Shiels MS, Machin M et al. Anal cancer risk among people with HIV infection in the United States. J Clin Oncol 2017; 36: 68-75.

6. Nigro ND, Vaitkevicius VK, Considine B. Combined therapy for cancer of the anal canal: a preliminary report. Dis Colon Rectum 1974; 17: 354-356.

7. Martin D, Balermpas P, Winkelmann R et al. Anal squamous cell carcinoma - State of the art management and future perspectives. Cancer Treat Rev 2018; 65: 11-21.

8. Lépinoy A, Lescut N, Puyraveau M et al. Evaluation of a 36 Gy elective node irradiation dose in anal cancer. Radiother Oncol 2015; 116: 197-201.

9. Epidermoid anal cancer: results from the UKCCCR randomised trial of radiotherapy alone versus radiotherapy, 5-fluorouracil, and mitomycin. UKCCCR Anal Cancer Trial Working Party. UK Co-ordinating Committee on Cancer Research. Lancet Lond Engl 1996; 348: 1049-1054.

10. Moureau-Zabotto L, Ortholan C, Hannoun-Levi J-M et al. Role of brachytherapy in the boost management of anal carcinoma with node involvement (CORS-03 Study). Int J Radiat Oncol 2013; 85: e135-142.

11. Glynne-Jones R, Nilsson PJ, Aschele C et al. Anal cancer: ESMO-ESSO-ESTRO clinical practice guidelines for diagnosis, treatment and follow-up. Eur J Surg Oncol EJSO 2014; 40: 1165-1176.

12. Cordoba A, Escande A, Leroy T et al. Low-dose-rate interstitial brachytherapy boost for the treatment of anal canal cancers. Brachytherapy 2017; 16: 230-235.

13. Pierquin B, Dutreix A, Paine $\mathrm{CH}$ et al. The Paris system in interstitial radiation therapy. Acta Radiol Oncol Radiat Phys Biol 1978; 17: 33-48.

14. LENT SOMA scales for all anatomic sites. Int J Radiat Oncol Biol Phys 1995; 31: 1049-1091.

15. Lund J-A, Kaasa S, Wibe A et al. Late radiation effects to the rectum and anus after treatment for prostate cancer; validity of the LENT/SOMA score. Acta Oncol 2013; 52: 727-735.

16. NCI Term Browser [https://ncit-stage.nci.nih.gov/ncitbrowser/pages/vocabulary.jsf?dictionary $=$ CTCAE\&version $=4.03$ cited $10^{\text {th }}$ Sep 2018].
17. Papillon J, Montbarbong JF, Gerard JP et al. Interstitial Curietherapie in the conservative treatment of anal and rectal cancers. Int J Radiat Oncol Biol Phys 1989; 17: 1161-1169.

18. Falk AT, Claren A, Benezery K et al. Interstitial high-dose rate brachytherapy as boost for anal canal cancer. Radiat Oncol 2014; 9: 240.

19. Gryc T, Ott O, Putz F et al. Interstitial brachytherapy as a boost to patients with anal carcinoma and poor response to chemoradiation: Single-institution long-term results. Brachytherapy 2016; 15: 865-872.

20. Hannoun-Levi J-M, Ortholan C, Resbeut M et al. High-dose split-course radiation therapy for anal cancer: outcome analysis regarding the boost strategy (CORS-03 Study). Int J Radiat Oncol Biol Phys 2011; 80: 712-720.

21. Northover J, Glynne-Jones R, Sebag-Montefiore D et al. Chemoradiation for the treatment of epidermoid anal cancer: 13-year follow-up of the first randomised UKCCCR Anal Cancer Trial (ACT I). Br J Cancer 2010; 102: 1123-1128.

22. Ajani JA, Winter KA, Gunderson LL et al. Fluorouracil, mitomycin, and radiotherapy vs fluorouracil, cisplatin, and radiotherapy for carcinoma of the anal canal: a randomized controlled trial. JAMA 2008; 299: 1914-1921.

23. Niehoff P, Kovács G. HDR brachytherapy for anal cancer. J Gastrointest Oncol 2014; 5: 218-222.

24. Frakulli R, Buwenge M, Cammelli $S$ et al. Brachytherapy boost after chemoradiation in anal cancer: a systematic review. J Contemp Brachytherapy 2018; 10: 246-253.

25. Oehler-Jänne C, Huguet F, Provencher S et al. HIV-specific differences in outcome of squamous cell carcinoma of the anal canal: a multicentric cohort study of HIV-positive patients receiving highly active antiretroviral therapy. J Clin Oncol 2008; 26: 2550-2557.

26. Das P, Crane $\mathrm{CH}$, Eng C, Ajani JA. Prognostic factors for squamous cell cancer of the anal canal. Gastrointest Cancer Res 2008; 2: 10-14.

27. Bruna A, Gastelblum P, Thomas L et al. Treatment of squamous cell anal canal carcinoma (SCACC) with pulsed dose rate brachytherapy: A retrospective study. Radiother Oncol 2006; 79: 75-79.

28. Wagner JP, Mahe MA, Romestaing P et al. Radiation therapy in the conservative treatment of carcinoma of the anal canal. Int J Radiat Oncol Biol Phys 1994; 29: 17-23.

29. Bartelink H, Roelofsen F, Eschwege F, et al. Concomitant radiotherapy and chemotherapy is superior to radiotherapy alone in the treatment of locally advanced anal cancer: results of a phase III randomized trial of the European Organization for Research and Treatment of Cancer Radiotherapy and Gastrointestinal Cooperative Groups. J Clin Oncol 1997; 15: 2040-2049.

30. Kapoor R, Khosla D, Shukla AK et al. Dosimetric and clinical outcome in image-based high-dose-rate interstitial brachytherapy for anal cancer. Brachytherapy 2014; 13: 388-393.

31. Kachnic LA, Winter K, Myerson RJ et al. RTOG 0529: A Phase 2 Evaluation of Dose-Painted Intensity Modulated Radiation Therapy in Combination With 5-Fluorouracil and Mitomycin-C for the Reduction of Acute Morbidity in Carcinoma of the Anal Canal. Int J Radiat Oncol 2013; 86: 27-33.

32. Deniaud-Alexandre E, Touboul E, Tiret E et al. Epidermoid carcinomas of anal canal treated with radiation therapy and concomitant chemotherapy (5-fluorouracil and cisplatin). Cancer/Radiothérapie 2006; 10: 572-582.

33. Tagliaferri L, Manfrida S, Barbaro B et al. MITHRA - multiparametric MR/CT image adapted brachytherapy (MR/ CT-IABT) in anal canal cancer: a feasibility study. J Contemp Brachytherapy 2015; 7: 336-345. 